Accepted refereed manuscript of: Odam N \& de Vries FP (2020) Innovatipn Wind Energy Technology. Energy Economics, 85, Art. No.: 104594. DOI https://doi.org/10.1016/j.eneco.2019.104594 (C) 2019, Elsevier. Licensed under the Creative Commons Attribution-NonCommercial-NoDerivatives 4.0 International http://creativecommons.org/licenses/by-nc-nd/4.0/

\title{
Innovation Modelling and Multi-Factor Learning in Wind Energy Technology*
}

\author{
Neil Odam Frans P. de Vries
}

Division of Economics, Stirling Management School, University of Stirling, Scotland, UK

September 2019

\begin{abstract}
Learning curves are frequently cited to justify the subsidization of new technologies to facilitate market competitiveness. The main literature has focused on improving the specification of the basic learning curve model by augmenting it to control for technological development measured by public R\&D expenditures. In addition to employing R\&D expenditures, the purpose of this paper is to assess the robustness of an augmented multi-factor learning curve model by estimating learning rates in a panel framework utilising patent data on relevant wind power technologies in Germany, Denmark, Spain and the UK. Results indicate that both innovation proxies are qualitatively identical and generate consistent learning estimates. The paper also aims at exploring the presence of unit roots in learning curves and alerts to the possibility of spurious estimations. Renewable energy policy guided by learning curve estimates should therefore be implemented with caution.
\end{abstract}

Keywords: Technical change, R\&D, Learning curves, Renewables, Patents, Knowledge stock, Unit roots JEL classification: D24; O30; Q28; Q48

\footnotetext{
* We would like to thank Nick Johnstone and Ivan Haščič of the OECD Environment Directorate for providing patent data based upon search strategies developed as part of the OECD Project on Environmental Policy and Technological Innovation (EPTI) (http://www.oecd.org/env/consumption-innovation/innovation.htm). We are also grateful to Asami Miketa, Thomas Sundqvist, Kristina Ek and Lena Neij for sharing relevant data, and to two anonymous referees, Nick Hanley, Patrik Söderholm, Ian Lange and Mirko Moro for useful comments. Neil Odam gratefully acknowledges the Economic and Social Research Council (ESRC) for a studentship through which this work was funded. The usual disclaimer applies.
} 


\section{Introduction}

Basic learning curves, specifying the relationship between a technology's cost reductions and cumulative installed capacity, are frequently cited in policy debates to justify the subsidization of renewable energy technologies (IEA, 2000; Weiss et al., 2010; Philibert, 2011). Learning curves have evolved from simple linear regression to two-factor learning curves (2FLC), attempting to capture the impact of technological innovation (the "knowledge stock") towards cost reduction, and further to multi-factor learning curves (MFLC) to encompass variables that contribute to technological cost reduction. As increasingly sophisticated techniques have been used to improve the specification of MFLC, it has also become apparent that potential econometric problems exist related to the estimation of learning curves, including the impact of scale effects (Söderholm and Sundqvist, 2007) and the potential presence of unit roots (Lindman and Söderholm, 2012).

This paper attempts to address both these issues simultaneously and stresses that, due to the combined nature of the econometric problems, the existing body of evidence on learning curves should be interpreted with caution. This has implications for the formation of energy technology policy based on learning curve estimates (Neij, 2008; Ferioli et al., 2009). For instance, in the context of climate change, a common argument in climate policy design rests on the idea that renewable energy technologies can become more costcompetitive by subsidizing an expansion of capacity (e.g., van der Zwaan and Seebregts, 2004) and by providing incentives for cost-reducing innovations through R\&D (Söderholm and Klaassen, 2007). However, Lindman and Söderholm (2012) show by means of a meta-analysis that learning rates for wind power vary widely.1 Substantial variability and uncertainty in learning rates has also been confirmed for a range of electric power generation technologies in systematic reviews by Rubin et al. (2015) and Samadi (2018). In the context of renewable energy technology the question then arises as to how the magnitude and variation in learning rates may affect associated policy formation.

One important complication related to estimating learning curves in MFLC specifications is that the knowledge stock is considerably more difficult to measure than cumulative capacity. Prior key literature has utilised public R\&D expenditure as a proxy for exogenous technological innovation (Klaassen et al., 2005; Söderholm and Sundqvist, 2007), but also in a way to endogenize R\&D effort in energy-wide systems (Barreto and Kypreos, 2004). The use of public R\&D expenditure as a proxy for the exogenous knowledge stock has led to the critique that the MFLC fails to account for relevant (private) sector R\&D, which might have different impacts on the cost of a technology compared to public R\&D (Yeh and Rubin, 2012). Instead, our paper contributes to the literature by employing patent data in constructing the knowledge stock component in the MFLC. In doing so, we make a closer link to the innovation "outputs" of the R\&D process, which allows for a direct comparison with the effect of public R\&D expenditures as an "input-based" measure of innovation on the performance of the MFLC. Lindman and Söderholm (2016) also employ patent data and public R\&D expenditures, but their model estimates the impact of $R \& D$ expenditure on the number of patent applications. In contrast, here we aim to compare $R \& D$ expenditures with patent data as two innovation proxies with respect

1 The highest learning rates estimates found exceed $30 \%$ whilst some estimates are even negative; see Table 1 in Lindman and Söderholm (2012) for the full list of papers that are included in their study. 
to their impact on investment costs. Grafström and Lindman (2017) build a patent-based knowledge stock as part of a comprehensive framework to study the dynamic interdependencies between the different stages of technological development, i.e., invention, innovation and diffusion. Given the explicit interaction between these three stages, the authors incorporate patents and R\&D expenditures simultaneously. Instead, we compare patents and R\&D expenditures "independently" with one another to examine whether they affect technological learning estimates differently. Given this direct comparison between these two innovation proxies, we then expand on this by looking more closely to the potential presence of unit roots (see Lindman and Söderholm, 2012).

Utilising patent count data, this paper constructs the knowledge stock variable for four major innovative countries in renewable energy technology: Germany, Denmark, Spain and the UK (e.g., Johnstone et al., 2010). We then combine this with data on the cost of generating electricity from on-shore wind farms and data on the average capacity of wind turbines in each of the aforementioned countries. Our empirical results indicate that capacity (the scale effect) is collinear with the knowledge stock, implying that the parameter estimates for both scale effect and innovation are likely to be inaccurate when estimated simultaneously. Further, the potential presence of unit roots is addressed by attempting to detect the presence of non-stationarity in the cost of wind turbines and cumulative capacity. The implications of non-stationarity are critical to the use of learning curves. As the analysis fails to reject the hypothesis that both costs and capacity are non-stationary, our findings suggest that learning curves produce spurious econometric results. A fundamental implication of utilising learning curve estimates may therefore be the undermining of an efficient design and implementation of energy policy tailored towards stimulating the expansion of renewable energy.

In what follows, Section 2 introduces the basic learning model framework. Section 3 describes the patent data used in this study and outlines the construction of the knowledge stock variable. Section 4 outlines the other data used in this paper and specifies the model to be estimated empirically. Section 5 presents the empirical results and Section 6 concludes.

\section{Basic Technology Learning Model}

This section introduces the learning curve model. We start off by setting up the basic one-factor learning curve (1FLC), followed by a discussion of the multi-factor learning curve (MFLC). As we will see, the MFLC is derived by augmenting the 1FLC with a measure of the knowledge stock associated with the technology in question, in our case wind power technology.

The basic 1FLC (Neij, 1997) is given as:

(1) $\quad S P C_{n, t}=A * C C_{n, t}^{\alpha}$

where $S P C_{n, t}$ is the specific investment cost of an energy technology per megawatt (MW) in country $n$ for a given year $t ; A$ is the cost of the first unit of capacity, $C C_{n, t}$ is the cumulative capacity in MW, and $\alpha>0$ represents the learning parameter. Following Neij (1997), learning curves are characterized by cost reductions 
of a constant percentage for each doubling of cumulative capacity. The percentage fall in cost per doubling of cumulative capacity can be written as:

$$
\frac{S P C_{n, t}-S P C_{n, t+1}}{S P C_{n, t}}=1-2^{\alpha}
$$

The term 1-2 $\alpha$ represents the Learning-by-Doing (LBD) rate, the general headline figure used to compare the potential cost reductions of different technologies.

A two-factor learning curve (2FLC) can be derived by augmenting the 1FLC with a measure of the knowledge stock associated for the technology in question. The main difference between the 1FLC and 2FLC model is that in the former cumulative capacity is implicitly capturing cost reductions from innovation, whilst the cost reductions from innovation in the 2FLC model are explicitly captured by including a knowledge stock variable. For instance, building upon the 2FLC model developed by Kouvaritakis et al. (2000), the study by Klaassen et al. (2005) uses R\&D expenditures as a proxy for the knowledge stock to construct the following functional specification:

$$
K S_{n, t}=(1-\delta) K S_{n, t-1}+R D_{n, t-x}
$$

where $K S_{n, t}$ denotes the R\&D-based knowledge stock at time $t ; R D_{n, t}$ is the R\&D expenditure in year $t ; x$ is a time lag for adding R\&D to the knowledge stock; and $\delta$ is the knowledge stock's annual depreciation rate. With the knowledge stock component modelled explicitly, the 2FLC can now be formulated as:

$$
S P C_{n, t}=A * C C_{n, t}^{\alpha} K S_{n, t}^{\beta}
$$

Alongside the learning index that is tied to cumulative capacity (parameter $\alpha$ ), the 2FLC specification in Eq. (4) now also captures learning related to the knowledge stock (parameter $\beta$ ). Whereas $1-2 \alpha$ is referred to as the LBD rate, the term $1-2 \beta$ is commonly referred to as the Learning-by-Searching (LBS) rate. With both LBD and LBS present in the 2FLC learning curve specification, one can more adequately identify the differential impact of cumulative capacity and the knowledge stock on learning, thereby allowing for improved predictions of expected future costs of technology.

\section{Construction of the Knowledge Stock}

The knowledge stock is designed to represent the accumulation of technological improvements over time. There are a number of ways to measure the stock of knowledge. A first and prominently used proxy is public R\&D expenditures (e.g., Klaassen et al., 2005; Söderholm and Sundqvist, 2007). Another proxy for the knowledge stock is simply counting the number of scientists and engineers engaged in research activities (e.g., Comanor and Scherer, 1969; Grafström and Lindman, 2017). Both these proxies are "input-based" measures of $R \& D$ in the sense that they give an indication of the "effort" put into the R\&D process without necessarily 
providing a basis for learning a developed technology that is already in place. In this respect, input-based measures only provide an indirect measure of potential inventive output and do not reveal the extent and size of actual inventive technological output generated.

A proxy for the knowledge stock that accounts for the amount of R\&D "output" produced can be derived from patent data. Patents provide an explicit indication of how much inventive output has been produced over time. One of the main advantages of patents over R\&D expenditures is technology-specificity, allowing one to track and assess the degree of innovation that occurred in a specific technological field in a given time period (Griliches, 1990). That is, patents are accurate in the sense that they are broken down by technology group, and combine detail and coverage of technologies. Furthermore, patents are particularly useful for studying technological change because of the detailed information they contain on the innovation or invention, the inventor country, and the country where the patent is registered (e.g., Popp, 2005), which is particularly useful in cross-country analyses. These features of patents, allowing data to be collected in disaggregated form, compare favourably to a more general statistic such as public R\&D expenditures if it involves the construction of a knowledge stock variable for a specific technology, such as wind power technology in our study.

Despite these advantages of using patent data, one also needs to be aware of some potential concerns. First, even though patents provide monopoly rights for firms' successful inventive output, it also requires firms to disclose the technological information as embedded in their inventions. However, firms may also choose not to file for patent protection and keep inventions from successful R\&D secret, implying that not all successful inventive output is patented. Second, the quality of the underlying inventions can vary considerably, making the value of patents heterogeneous across the technological spectrum. Our patent data - to be described in more detail below - does not discriminate between high and low value patents, however. Third, patent regulations may differ across countries, making international comparisons more challenging (e,g., Lanjouw et al., 1998). However, since we are assessing differences in trends rather than comparing levels of patenting activity, this is not so much of a problem in our panel structure comprising multiple countries (e.g., Popp et al., 2011).

We employ patent data on wind power technology, particularly patents in relation to the actual development of wind turbines (motors), which is the relevant key technology. This implies that our focal technologies primarily encompass the manufacturing process of wind turbines and do not represent technologies related to the assembly and on-site installation of wind turbines. While the patent classes could have been expanded to encompass patents related to assembly and on-site installation, the trade-off is an increasing likelihood of incorrectly included patents that are not directly related to the actual development of more efficient and effective wind motor technology.

Patents were extracted from the European Patent Office's PATSTAT database to obtain patent counts by inventor countries for a range of inventions relevant for the development of wind energy technology. To extract the relevant patents from PATSTAT, we first searched the European Patent Office's user interface, Espacenet2, to identify the classes containing patents which are relevant for wind power technology. The selected classes 
that were used are listed in Table 1. The main patent class containing inventions on wind power technology is F03D, which relates to inventions on the rotation, control and adaptation of wind motors, including technical and aerodynamic properties of the blades. The patent counts were based on claimed priorities. These are inventions for which protection has been sought in at least one country, in addition to the country where the first patent application was filed (the priority office). Rather than using all patent applications, employing claimed priority patents minimizes the inclusion of low value patents, because firms have a 12-month time window in which they can evaluate whether their initial patent is sufficiently valuable to justify the cost of extending their patent protection to countries other than the country where the patent was initially filed (e.g., Popp et al., 2011).3 The PATSTAT database, a comprehensive record of worldwide patents, has the capacity to identify valuable patents by distinguishing between low cost initial patent filings and higher cost "claimed priority" filings, which have been claimed in at least one foreign country.

Table 1: Patent classes extracted for wind power knowledge stock

\begin{tabular}{ll}
\hline Patent class & Description \\
\hline F03D & Wind motors \\
F03D1 & Wind motors with rotation axis substantially in wind direction \\
F03D3 & Wind motors with rotation axis substantially at right-angles to wind direction \\
F03D5 & Other wind motors \\
F03D7 & Controlling wind motors \\
F03D9 & Adaptations of wind motors for special use \\
F03D11 & Details, component parts, or accessories not provided for in preceding groups \\
\hline
\end{tabular}

Source: Espacenet, European Patent Office

Given the availability of cumulative capacity and investment cost data for wind energy, patents were extracted for four major innovating countries in the wind power industry: Denmark, Germany, Spain and the UK. A graphical representation of cumulative patent counts from 1981 to 2001 for these countries is given in Figure 1. Overall, Figure 1 conveys that all these four countries experience a positive trend in the level of patenting over time. Germany features the highest level of patenting and shows a steady increase in the number of patent applications since the early 1980s. Denmark's rising trend in patenting behaviour is roughly the same as in Germany, but at a lower absolute level. Patenting in the UK kicks off steeply as of 1982 but levels off in the mid 1980s, showing a small but positive growth in the number since. Innovative activity in Spain ignites as of 1991 after which a very sharp increase in the number of patent applications is witnessed, reaching a higher level of patenting than the UK in the late 1990s.

3 Restricting the measurement of innovation to these higher cost claimed priority filings should avoid the issue of frivolous patents. See Jamasb (2007) for a study that utilises an unrestricted count of patents. 


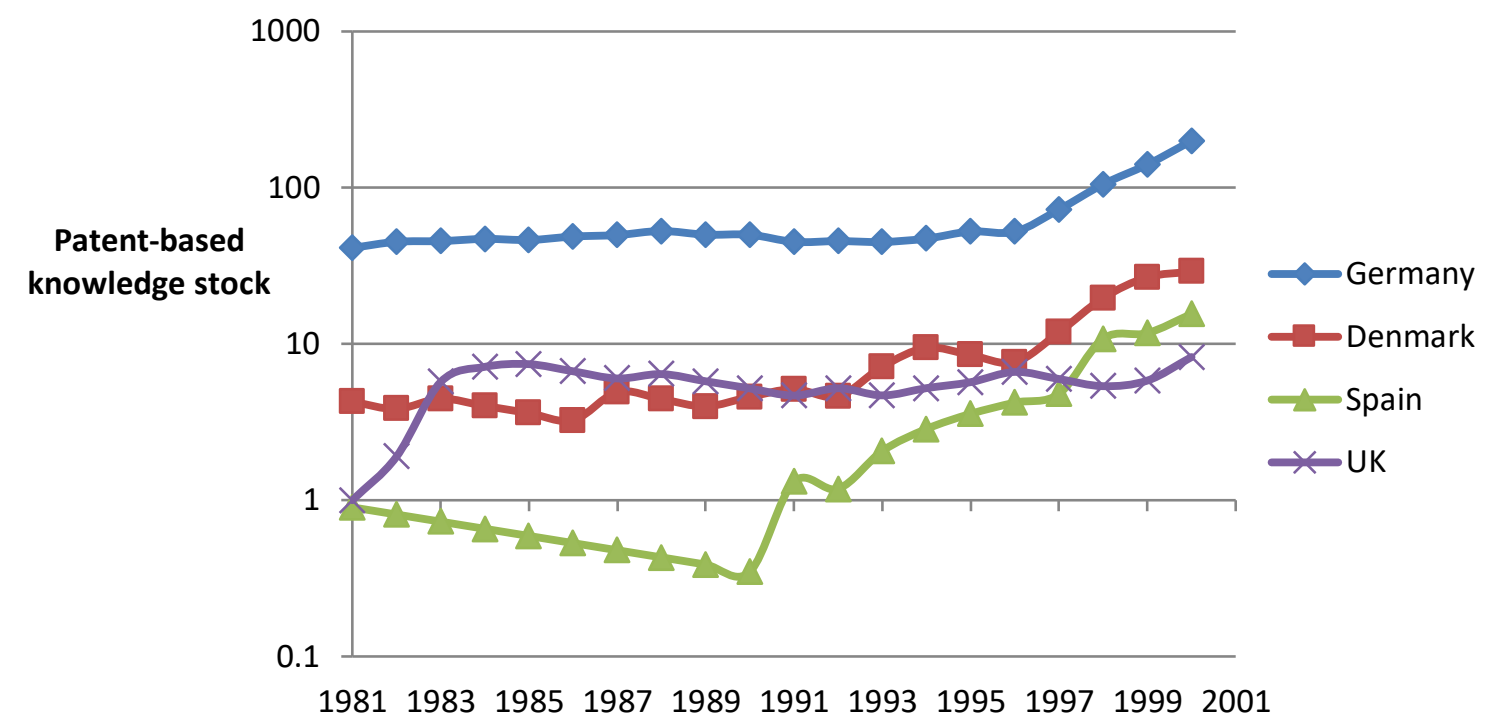

Figure 1: Cumulative patent counts for Germany, Denmark, Spain and UK (1981-2001)

Source EPO (2010) and own calculations

Table 2 displays the absolute number of claimed priority patents filed by each country as well descriptive statistics on the normalized number of patents for each country. Since some countries have high levels of patenting across all technologies, normalising patents in this way has been used by Johnstone et al. (2010) to control for country-specific patenting behaviour as well as to recognise that smaller countries often specialise in specific industries more than large countries. A clear example of this is Denmark with a strong specialisation in wind turbine development.

Table 2: Descriptive patent statistics for selected countries in 1981-2001a)

\begin{tabular}{lllllllll}
\hline & Germany & \multicolumn{3}{c}{ Denmark } & UK & \multicolumn{3}{c}{ Spain } \\
\hline & Cum. & Norm. & Cum. & Norm. & Cum. & Norm. & Cum. & Norm. \\
& Patents & Patents & Patents & Patents & Patents & Patents & Patents & Patents \\
\hline Observations & 21 & 21 & 21 & 21 & 21 & 21 & 21 & 21 \\
Mean & 117.23 & 0.54 & 14.67 & 2.44 & 4.26 & 2.38 & 9.93 & 0.47 \\
St. deviation & 66.72 & 0.10 & 11.19 & 0.87 & 5.55 & 1.89 & 4.72 & 0.17 \\
Minimum & 43.8 & 0.44 & 6.00 & 1.58 & 1.00 & 0.60 & 0.00 & 0.00 \\
Maximum & 318.38 & 0.82 & 45.00 & 4.59 & 20.50 & 7.76 & 18.50 & 0.78 \\
\hline
\end{tabular}

a) Normalized cumulative patens in brackets (per 1,000 claimed patents); source EPO (2010) and own calculations 


\section{Model Specification and Data Description}

Compared to the fundamental 2FLC model as shown in Eq. (4), an extended version of this model not only explains how investment costs $(S P C)$ relate to cumulative capacity $(C C)$ and the knowledge stock $(K S)$, but also includes covariates such as scale effects (SCALE), government support through feed-in tariffs (FIT) and a commodity index $(C O M)$. The contemporary fixed effects specification including these covariates then reads as follows:

(5) $\ln S P C_{n, t}=\alpha_{n}+\theta_{t}+\ln \beta_{0}+\beta_{1} \ln C C_{n, t}+\beta_{2} \ln K S_{n, t}+\beta_{3} \ln S C A L E_{n, t}+\beta_{4} \ln F I T_{n, t}+\beta_{5} \ln C O M_{t}+\varepsilon_{n, t}$

where $\alpha_{n}$ refers to country fixed effects, $\theta_{t}$ time fixed effects, $\varepsilon_{n, t}$ is the error term, and subscripts $n$ and $t$ denote country and year, respectively. We use cumulative capacity figures and windmill investment costs (US\$ per kW)4 obtained from Söderholm and Sundqvist (2007) for Denmark from 1986-1999, Germany from 19901999, the UK from 1991-2000 and Spain from 1990-1999. All price and cost data are expressed in U.S. dollars using 1998 as base year. Table 3 contains the descriptive statistics of the data used for the econometric analyses.

It is important to emphasise the diverse range of cost reductions which contribute to the learning curve to avoid excessive focus on the most intuitive cost reduction: those relating only to manufacturing the product. The International Energy Agency (IEA, 2000) asserts that cost reductions related to improved site selection, tailoring devices to the individual site, maintenance and power management should be included in learning curves. In addition, scaling effects, product standardization and input prices affect technological learning (Neij, 1997; Yu et al., 2011; Panzer, 2012). This signifies the importance of these additional non-manufacturing cost sources.

A further distinction concerns learning-by-doing and economies of scale. Economies of scale are simply the dilution of overhead costs over a larger number of units, thus reducing the cost per unit.5 Learning-bydoing refers to cost reductions through increased efficiency or technological innovation. It is vital to separately account for the scale effect in learning curves, since this component is unlikely to share the same cost reduction percentage over multiple orders of magnitude. Failure to account for this will lead to an over-estimation of the potential cost savings that could be achieved from innovation or enhanced cumulative capacity. In this paper, economies of scale were considered by calculating the average power output of wind turbines installed in Denmark, Germany, Spain and the UK. This is illustrated in Figure 2. While it is unlikely to fully account for cost reductions from economies of scale, it can be calculated rather accurately and is likely to capture much of the scale effect. An attempt has also been made to encompass input prices (e.g., steel prices) for wind power projects by using the industrial material index from the International Monetary Fund (IMF, 2011). With respect

4 In addition to the investment cost of the wind turbines, this also includes investment costs such as grid connections, foundations and electrical connections.

5 The change in the logged unit costs of technology, as well as logged scaling effects, could be linear or non-linear over time. We tested for (non)linearity statistically by using the Ramsey test. Running this test produces an $F$-value of 0.4565 , which fails to reject that the squared fitted values are equal to 0 (see Stata file). This suggest a linear relationship between the variables investment costs and scaling. Eq. (5) therefore features a linear specification. 
to input prices we assume that, given the international character of such markets, these have a time component but not a country-specific component.

Table 3: Descriptive statistics of data used in panel data estimation

\begin{tabular}{|c|c|c|c|c|}
\hline Investment Costs (SPC) & Denmark & Germany & UK & Spain \\
\hline No. Observations & 14 & 10 & 10 & 10 \\
\hline Mean & $1,406.00$ & $1,628.70$ & $1,750.70$ & $1,593.40$ \\
\hline St. Dev. & 240.22 & 288.91 & 320.97 & 354.45 \\
\hline Min & $1,039.00$ & $1,338.00$ & $1,306.00$ & $1,202.00$ \\
\hline Max & $1,828.00$ & $2,070.00$ & $2,193.00$ & $2,268.00$ \\
\hline Period & 1986-1999 & 1990-1999 & $1991-2000$ & 1990-1999 \\
\hline \multicolumn{5}{|l|}{ Cumulative Capacity $(C C)$} \\
\hline No. Observations & 14 & 10 & 10 & 10 \\
\hline Mean & 618.46 & $1,317.17$ & 212.51 & 348.10 \\
\hline St. Dev. & 499.33 & $1,425.79$ & 137.41 & 509.02 \\
\hline Min & 82.60 & 59.80 & 4.00 & 0.01 \\
\hline Max & $1,744.00$ & $4,400.00$ & 406.00 & $1,584.00$ \\
\hline Period & 1986-1999 & 1990-1999 & $1991-2000$ & 1990-1999 \\
\hline \multicolumn{5}{|l|}{ Feed-In Tariff (FIT) } \\
\hline No. Observations & 14 & 10 & 10 & 10 \\
\hline Mean & 10.28 & 11.08 & 13.41 & 9.34 \\
\hline St. Dev. & 1.14 & 1.34 & 7.28 & 1.73 \\
\hline Min & 8.38 & 8.89 & 5.00 & 7.09 \\
\hline $\operatorname{Max}$ & 12.31 & 12.78 & 21.47 & 12.30 \\
\hline Period & 1986-1999 & 1990-1999 & $1991-2000$ & 1990-1999 \\
\hline \multicolumn{5}{|l|}{ Scale $(S C A L E)$} \\
\hline No. Observations & 15 & 11 & 10 & 11 \\
\hline Mean & 367.37 & 509.50 & 505.61 & 345.45 \\
\hline St. Dev. & 243.51 & 326.69 & 127.69 & 207.44 \\
\hline Min & 130.00 & 164.30 & 317.50 & 90.00 \\
\hline $\operatorname{Max}$ & 904.76 & $1,113.80$ & 744.10 & 653.00 \\
\hline Period & $1986-2000$ & $1990-2000$ & $1991-2000$ & $1990-2000$ \\
\hline \multicolumn{5}{|l|}{ Commodity index (COM) } \\
\hline No. Observations & 15 & 11 & 10 & 11 \\
\hline Mean & 79.89 & 80.49 & 79.94 & 80.49 \\
\hline St. Dev. & 10.39 & 7.65 & 7.83 & 7.65 \\
\hline Min & 56.41 & 71.33 & 71.33 & 71.33 \\
\hline Max & 94.57 & 94.57 & 94.57 & 94.57 \\
\hline Period & $1986-2000$ & $1990-2000$ & $1991-2000$ & $1990-2000$ \\
\hline
\end{tabular}

Sources: SPC, CC and FIT: Söderholm and Sundqvist (2007); SCALE: see Figure 2; COM: IMF (2011) 


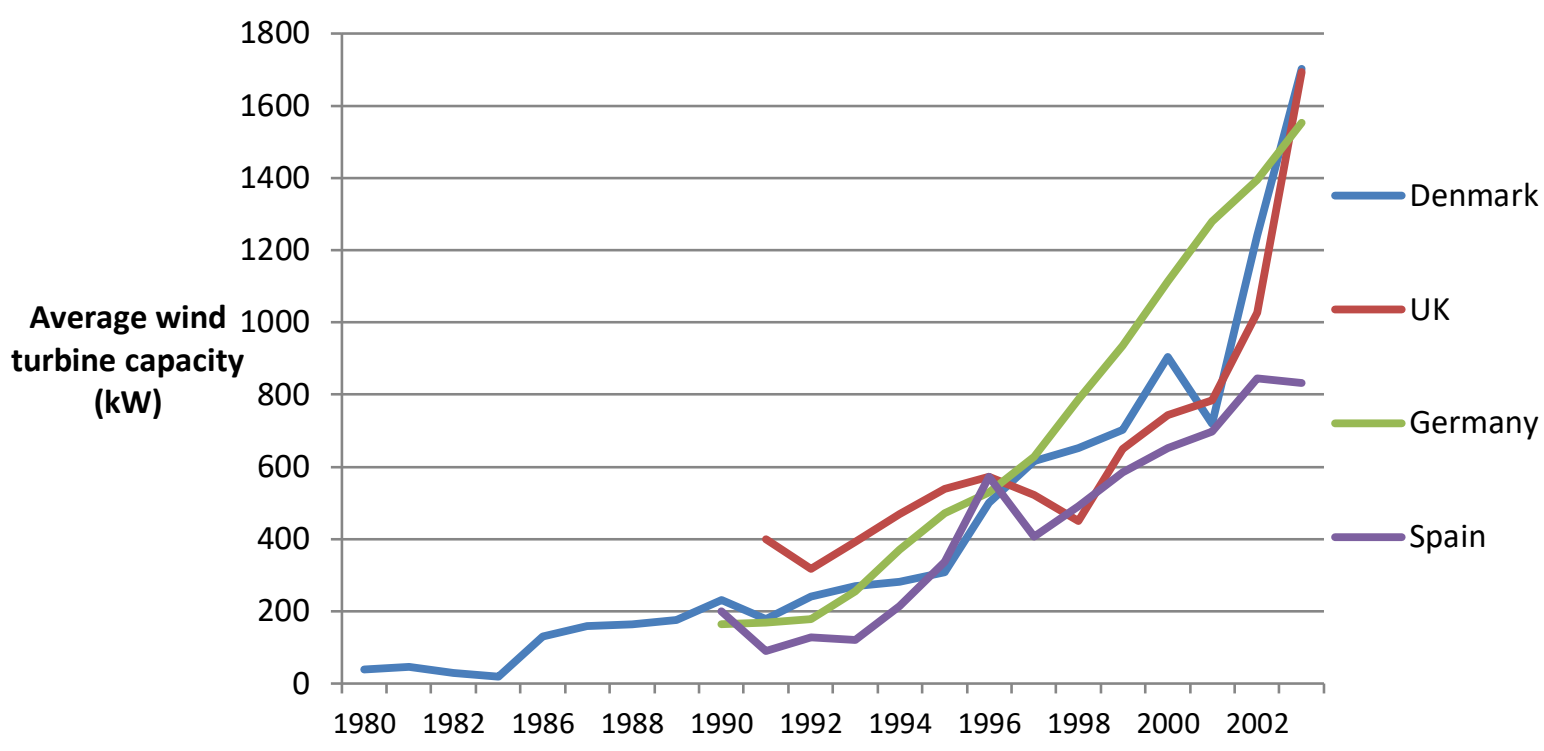

Figure 2: Average wind turbine capacity in Germany, Denmark, Spain and UK (1979-2003)

Sources: Danish Energy Agency (2010), Renewable UK (2011), Molly-DWEI (2007), Spanish Wind Energy Association (2008) 


\section{Results}

Table 4 displays the fixed-effects panel regressions6 of the extended 2FLC model as given by Eq. (5).7 We show results using four different measures of the knowledge stock, denoted I, II, III and IV. In variant I we make use of the public R\&D-based knowledge stock taken from Söderholm and Sundqvist (2007). Variant II uses the same public R\&D-based knowledge stock, but with updated values from the International Energy Agency database (IEA, 2011). In variant III and IV we use our own constructed knowledge stock based on cumulative patents and normalized cumulative patents, respectively, as outlined in Section 3. It is standard practice in the technological change literature to account for depreciation of R\&D (e.g., Griliches 1979). In this paper, the knowledge stock is created by applying a 1-year lag and, following Klaassen et al. (2005), a 3\% depreciation rate to the cumulative patent count for each country. Note that by using the domestic cumulative capacity and knowledge stock, we are implicitly assuming the absence of international learning spillovers.8 Furthermore, all four specifications are estimated with and without the SCALE effect variable, denoted by model extension "b" and "a" in Table 4, respectively.

Table 4: Regression results for 2FLC model

\begin{tabular}{|c|c|c|c|c|c|c|c|c|}
\hline $\begin{array}{l}\text { Dependent variable: } \\
\text { Investment costs }(\ln S P C)\end{array}$ & I-a & I-b & II-a & II-b & III-a & III-b & IV-a & IV-b \\
\hline Constant & $\begin{array}{l}8.177 * * \\
(26.76)\end{array}$ & $\begin{array}{l}8.896^{* *} \\
(17.38)\end{array}$ & $\begin{array}{l}8.325^{* *} \\
(24.92)\end{array}$ & $\begin{array}{l}8.936^{* *} \\
(17.20)\end{array}$ & $\begin{array}{l}7.48^{* *} \\
(43.73)\end{array}$ & $\begin{array}{l}8.898^{* *} \\
(17.20)\end{array}$ & $\begin{array}{l}7.904 * * \\
(34.5)\end{array}$ & $\begin{array}{l}9.013^{* *} \\
(17.17)\end{array}$ \\
\hline Cumulative Capacity $(\ln C C)$ & $\begin{array}{l}-0.051 * * \\
(-5.74)\end{array}$ & $\begin{array}{l}-0.038^{* *} \\
(-4.51)\end{array}$ & $\begin{array}{l}-0.050 * * \\
(-5.76)\end{array}$ & $\begin{array}{l}-0.038 * * \\
(-4.52)\end{array}$ & $\begin{array}{l}-0.034^{*} \\
(-2.44)\end{array}$ & $\begin{array}{l}-0.034 * * \\
(-2.94)\end{array}$ & $\begin{array}{l}-0.045^{* *} \\
(-4.72)\end{array}$ & $\begin{array}{l}-0.037 * * \\
(-4.33)\end{array}$ \\
\hline Knowledge Stock $(\ln K S)$ & $\begin{array}{l}-0.221 * * \\
(-3.46)\end{array}$ & $\begin{array}{l}-0.049 \\
(-0.69)\end{array}$ & $\begin{array}{l}-0.225 * * \\
(-3.58)\end{array}$ & $\begin{array}{l}-0.056 \\
(-0.78)\end{array}$ & $\begin{array}{l}-0.134^{*} \\
(-2.69)\end{array}$ & $\begin{array}{l}-0.031 \\
(-0.57)\end{array}$ & $\begin{array}{l}-0.230^{* *} \\
(-3.63)\end{array}$ & $\begin{array}{l}-0.085 \\
(-1.09)\end{array}$ \\
\hline Scale $(\ln S C A L E)$ & & $\begin{array}{l}-0.135^{* *} \\
(-3.49)\end{array}$ & & $\begin{array}{l}-0.133^{* *} \\
(-3.40)\end{array}$ & & $\begin{array}{l}-0.136 * * \\
(-3.33)\end{array}$ & & $\begin{array}{l}-0.118^{* *} \\
(-2.73)\end{array}$ \\
\hline Feed-in Tariff $(\ln F I T)$ & $\begin{array}{l}0.160 * * \\
(3.13)\end{array}$ & $\begin{array}{l}0.139 * * \\
(3.04)\end{array}$ & $\begin{array}{l}0.158^{* *} \\
(3.12)\end{array}$ & $\begin{array}{l}0.139 * * \\
(3.04)\end{array}$ & $\begin{array}{l}-0.172 * * \\
(3.22)\end{array}$ & $\begin{array}{l}0.143 * * \\
(3.11)\end{array}$ & $\begin{array}{l}0.131^{*} \\
(2.49)\end{array}$ & $\begin{array}{l}0.133^{* *} \\
(2.89)\end{array}$ \\
\hline Commodity (ln COM) & & $\begin{array}{l}-0.154 \\
(-1.32)\end{array}$ & & $\begin{array}{l}-0.153 \\
(-1.31)\end{array}$ & & $\begin{array}{l}-0.190 \\
(-1.55)\end{array}$ & & $\begin{array}{l}-0.197 \\
(-1.68)\end{array}$ \\
\hline LBD rate $(\%)$ & 3.43 & 2.62 & 3.42 & 2.62 & 2.32 & 2.34 & 3.04 & 2.53 \\
\hline LBS rate $(\%)$ & 14.19 & 3.37 & 14.42 & 3.80 & 8.84 & 2.13 & 14.71 & 5.72 \\
\hline Adjusted $\mathrm{R}_{2}$ & 0.78 & 0.83 & 0.78 & 0.84 & 0.75 & 0.83 & 0.78 & 0.84 \\
\hline
\end{tabular}

All model specifications have been estimated including year dummies; $t$-statistic in parenthesis; $*$ and $* *$ denote statistical significance at $5 \%$ and $1 \%$ level, respectively.

6 The Hausman test (1978) and the Breusch-Pagan Lagrange Multiplier test (Breusch and Pagan, 1980) were used to determine whether fixed or random effects should be included. Both tests confirmed that random effects were not appropriate; each specification therefore included fixed effects.

7 All regressions were conducted in Stata; the supplementary code and data is available online.

8 Ek and Söderholm (2010) discuss the theoretical implications of learning spillovers and show that it is difficult to empirically estimate the effect of spillovers in learning curves. As this issue is beyond the scope of our paper, we leave this for future research. 
The empirical findings as shown in Table 4 reveal that the use of a patent-based knowledge stock (model III and IV) does not inherently provide different estimates compared to the use of a public R\&D knowledge stock (model I and II). In all four model specifications the investment costs are negatively related to the knowledge stock (as expected), though they are all statistically insignificant. Thus, using public R\&D investments as an input-based measure or patents as an output-based measure of the R\&D process is qualitatively similar. However, the systematic insignificance of the knowledge stock is caused due to its collinear relationship with the scale effects variable (SCALE). Further, the analysis overall reveals that LBD rates are consistently lower than LBS rates, except in model specification III-b. This result suggests that learning models which fail to include a measure of innovation over-estimate LBD rates and may potentially mislead the design and evaluation of renewable energy policy and programmes.

Assessing the findings through the lens of feed-in tariffs (FIT), we find a positive and significant effect on investment costs. This is in line with Söderholm and Sundqvist (2007) who identify two reasons for this effect. First, feed-in tariffs incentivise electric power firms to increasingly develop marginal wind power sites. These sites may either have more expensive grid connections or face wind conditions which are worse than the average wind power site. This, in turn, raises the average price of wind power projects. Second, feed-in tariffs act to reduce competition with other energy sources, which subsequently may adversely impact the incentive to innovate.9 Finally, complementing the estimations with the commodity index does not seem to add explanatory power, and whilst it systematically reveals a negative impact on investment costs, it is statistically insignificant across the relevant model specifications.

Cumulative capacity and the knowledge stock embody data generating processes which are likely to produce data containing a unit root. If the data generating process of cumulative capacity is non-stationary, then it is possible that learning curves produce spurious results. In the past two decades unit root tests have been devised specifically for panel data (Harris and Tzavalis, 1999). More recently, tests have been devised for this purpose that are more robust to small sample sizes in panel data. The Breitung unit root test (Breitung and Das, 2005) appears to be the most appropriate for a limited sample sizes, such as in this study. The ImPesaran-Shin test (Im et al., 2003) is also suitable for small sample sizes and offers the option to choose the Augmented Dickey Fuller (ADF) lag structure using goodness of fit tests, such as the Akaike Information Criterion (AIC). The null hypothesis of the Breitung test is that the panel contains a unit root, whilst the null hypothesis of the Im-Pesaran-Shin test is that all the panels contain unit roots. Adopting the Breitung test requires a balanced panel, which implied that the data set was reduced to four panels with 9 periods each.

Table 5 contains the results of a variety of specifications testing for unit roots in cumulative capacity. Each specification of the Breitung test suggests that cumulative capacity contains a unit root. The Im-PesaranShin test produces the same results, except where the ADF lag term is chosen by the AIC. It is likely that cumulative capacity is non-stationary and the trend non-stationary. Only if the AIC-determined ADF lag structure can be justified should it be concluded that learning models are valid in their current form. Table 5

9 Lindman and Söderholm (2016) empirically show for a selection of four European countries (Germany, Denmark, Spain and Sweden) that feed-in tariffs positively impacted innovation (measured in terms of patent applications). 
includes the results of the same tests applied to the investment cost data used in this paper. On this occasion, each specification fails to reject the hypothesis that the investment cost contains a unit root. The presence of unit roots in time series variables have been shown to produce spurious results in linear regression analysis (Granger and Newbold, 1974). However, as noted by Lindman and Söderholm (2012), if cumulative capacity and investment costs share a common stochastic trend then the two variables would be cointegrated, dispelling the problem of spurious results.

Table 5: Unit root tests of $l c a p_{n t}$ and $l_{i n v_{n} t}$ (p-values)

\begin{tabular}{|c|c|c|c|c|}
\hline & \multicolumn{2}{|c|}{ Breitung } & \multicolumn{2}{|c|}{ Im-Pesaran-Shin } \\
\hline & lcapnt & linvnt & lcapnt & $\operatorname{linv} n t$ \\
\hline No trend & 0.999 & 0.912 & 0.668 & 0.743 \\
\hline Trend & 0.851 & 0.147 & 0.393 & 0.219 \\
\hline $\operatorname{Lag}(1)$ & 0.5405 & 0.6587 & 0.7979 & 0.734 \\
\hline $\begin{array}{l}\text { Lag (AIC) } \\
\text { (AIC lag length) }\end{array}$ & & & $\begin{array}{r}0.0000^{* *} \\
(0.25 \text { lags })\end{array}$ & $\begin{array}{r}0.819 \\
(0.00 \text { lags })\end{array}$ \\
\hline Trend and lag (1) & 0.224 & 0.546 & $0.0001 * *$ & 0.355 \\
\hline $\begin{array}{l}\text { Trend and lag (AIC) } \\
\text { (AIC lag length) }\end{array}$ & - & - & $\begin{array}{r}0.0001 * * \\
(0.75 \text { lags })\end{array}$ & $\begin{array}{r}0.337 \\
(0.50 \text { lags })\end{array}$ \\
\hline
\end{tabular}

Table 6: Westerlund test for cointegration

\begin{tabular}{|l|r|r|r|}
\hline Statistic & Value & $Z$-value & $P$-value \\
\hline$G t$ & - & - & - \\
$G a$ & -10.564 & 0.401 & 0.656 \\
$P t$ & -44.405 & -46.800 & $0.000 * *$ \\
$P a$ & -10.304 & -0.452 & 0.326 \\
\hline \multicolumn{3}{|l|}{} \\
** Statistical significance at 1\% level.
\end{tabular}


Table 6 displays the results of the Westerlund (2007) test for cointegration. $G t$ and $G a$ test for cointegration in the group means; $P t$ and $P a$ test for cointegration in the panel as a whole. Both tests have the null hypothesis that there is no cointegration. $G t$ and $P t$ set the number of leads and lags in the test based on the number of years in the data, whereas $G a$ and $P a$ set the number of leads and lags in the test based on the AIC. Given that $G t$ has failed to estimate results, it is clear that the low sample size may impact the overall test results. The panel test, Pt, with leads and lags based on the number of years in the data, does indicate that cumulative capacity and investment costs are cointegrated. Both the group mean and panel test, using AIC to choose the leads and lags in the test, both fail to reject the null hypothesis that there is no cointegration. With the sample size currently available for wind power it appears that investment costs and cumulative capacity are both non-stationary and cannot be said to be cointegrated. This suggests that learning curves are likely to produce spurious results.

\section{Concluding Remarks}

Previous research on learning curves, attempting to encompass the theoretical foundations for technological learning (i.e., multi-factor learning), has predominantly utilized public R\&D expenditures as an R\&D “inputbased" measure of innovation (i.e., the knowledge stock). In addition to using public R\&D data, this paper employs patent data on wind power technology as an R\&D "output-based" measure of innovation to model and estimate learning curves. We construct an exogenous measure of technological progress by identifying patent applications related to key wind power technologies in four European countries with a significant wind power industry: Germany, Denmark, Spain and the UK.

Our findings suggest that public R\&D and patent counts are qualitatively similar and that exclusion of a country's knowledge stock - as in one-factor learning curve specifications - is likely to result in an overestimation of the learning-by-doing rate. Although multi-factor learning models provide more accurate estimates by accounting for the knowledge stock, a potential drawback of these models is that it is considerably more difficult to measure than cumulative capacity, which is the only independent variable of concern in the one-factor learning model. Results reveal that the scale effect tends to be collinear with the knowledge stock. Empirically this means that estimates for the knowledge stock and scale effect are biased when estimated simultaneously in one single model. Results from unit root tests suggest that learning curves based on cumulative capacity are likely to be spurious. Furthermore, robustness checks conducted to control for exogenous changes (by including time trends or year dummies) also confirm collinearity. This finding is in line with results obtained by Söderholm and Sundqvist (2007) and adds to Nordhaus's (2014) argument that it is difficult to separate out exogenous and endogenous technological progress.

Overall, our study signifies the importance of modelling technological dynamics in estimating learning rates and argues that care is needed when interpreting estimated learning rates. The contentious dynamic nature between the knowledge stock and cumulative capacity has important implications for (many) emerging energy technologies and the corresponding design of energy policy (Isoard and Soria, 2001). In our case this implies 
that models based on learning curves can mislead the optimal formation of renewable energy policy. For instance, where the impact of learning rates is over-estimated, subsidies based on these learning rates are likely to be inefficient.

\section{References}

Barreto, L. and Kypreos, S. (2004), "Endogenizing R\&D and market experience in the 'bottom-up' energysystems ERIS model," Technovation 24: 615-629.

Breusch, T.S. and Pagan, A.R. (1980), "The Lagrange multiplier test and its applications to model specification in econometrics," Review of Economic Studies 47: 239-253.

Breitung, J. and Das, S. (2005), "Panel unit root tests under cross-sectional dependence," Statistica Neerlandica 59: 414-433.

Comanor, W.S. and Scherer, F.M. (1969), "Patent statistics as a measure of technical change," Journal of Political Economy 77: 392-398.

Danish Energy Agency (2010), Stamdataregister for vindkraftanlæg ultimo maj 2008 (last accessed 10th November 2010).

Ek, K. and Söderholm, P. (2010), "Technology learning in the presence of public R\&D: The case of European wind power," Ecological Economics 69: 2356-2362.

European Patent Office (2010), Esp@cenet user interface (available at www.epo.org).

Ferioli, F., Schoots, K. and van der Zwaan, B.C.C. (2009), "Use and limitations of learning curves for energy technology policy: A component-learning hypothesis," Energy Policy 37: 2525-2535.

Grafström, J. and Lindman, Å. (2017), "Invention, innovation and diffusion in the European wind power sector," Technological Forecasting and Social Change 114: 179-191.

Granger, C.W. and Newbold, P. (1974), "Spurious regressions in econometrics," Journal of Econometrics 2: 111-120.

Griliches, Z. (1979), "Issues in assessing the contribution of research and development to productivity growth", The Bell Journal of Economics 10: 92-116.

Griliches, Z. (1990), "Patent statistics as economic indicators: A survey," Journal of Economic Literature 28: 1661-1707.

Harris, R. and Tzavalis, E. (1999), "Inference for unit roots in dynamic panels where the time dimension is fixed," Journal of Econometrics 91: 201-226.

Hausman, J.A. (1978), "Specification tests in econometrics," Econometrica 46: 1251-1271.

IEA (International Energy Agency) (2000), Experience Curves for Energy Technology Policy, OECD/IEA, Paris.

IEA (International Energy Agency) (2011), IEA Guide to Reporting Energy RD\&D Budget/Expenditure Statistics, June 2011 Edition, OECD/IEA, Paris.

Im, K.S., Pesaran, M.H. and Shin, Y. (2003), "Testing for unit roots in heterogeneous panels," Journal of Econometrics 115: 53-74.

IMF (International Monetary Fund) (2010), IMF Primary Commodity Prices. 
Isoard, S. and Soria, A. (2001), "Technical change dynamics: Evidence from the emerging renewable energy technologies," Energy Economics 23: 619-636.

Jamasb, T. (2007), "Technical change theory and learning curves: Patterns of progress in electricity generation technologies," The Energy Journal 28: 51-72.

Johnstone, N., Hascic, I. and Popp, D. (2010), "Renewable energy policies and technological innovation: Evidence based on patent counts," Environmental and Resource Economics 45: 133-155.

Klaassen, G., Miketa, A., Larsen, K. and Sundqvist, T. (2005), "The impact of R\&D on innovation for wind energy in Denmark, Germany and the United Kingdom," Ecological Economics 54: 227-240.

Kouvaritakis, N., Soira, A. and Isoard, S. (2000), "Modelling energy technology dynamics: Methodology for adaptive expectations models with learning by doing and learning by searching", International Journal of Global Energy Issues 14: 104-115.

Lanjouw, J., Pakes, A. and Putnam, J. (1998), "How to count patents and value intellectual property: The uses of patent renewal and application data," Journal of Industrial Economics 46: 405-432.

Lindman, Å. and Söderholm, P. (2012), "Wind power learning rates: A conceptual review and meta-analysis," Energy Economics 34: 754-761.

Lindman, A. and Söderholm, P. (2016), "Wind energy and green economy in Europe: Measuring policyinduced innovation using patent data," Applied Energy 179: 1351-1359.

Molly, J.P. (2007), DWEI GmbH, Ermittlung der deutschen Wertschopfung im weltweiten Windenergiemarkt für 2007.

Neij, L. (1997), "Use of experience curves to analyse the prospects for diffusion and adoption of renewable energy technology," Energy Policy 23: 1099-1107.

Neij, L. (2008), “Cost development of future technologies for power generation - A study based on experience curves and complementary bottom-up assessments," Energy Policy 36: 2200-2211.

Nordhaus, W.D. (2014), “The perils of the learning model for modeling endogenous technological change," The Energy Journal 35: 1-13.

Philibert, C. (2011), Solar Energy Perspectives, International Energy Agency, France.

Panzer, C. (2012), Investment Costs of Renewable Electricity Technologies: The Impact of Learning Effects and Volatile Energy and Raw Material Prices, Südwestdeutscher Verlag für Hochschulschriften.

Popp, D. (2005), "Lessons from patents: Using patents to measure technological change in environmental models," Ecological Economics 54: 209-226.

Popp, D., Hascic, I. and Medhi, N. (2011), “Technology and the diffusion of renewable energy," Energy Economics 33: 648-662.

Renewable UK (2011), UK Wind Energy Database.

Rubin, E.S., Azevedo, I.M.L., Jaramillo, P. and Yeh, S. (2015), “A review of learning rates for electricity supply technologies," Energy Policy 86: 198-218.

Samadi, S. (2018), "The experience curve theory and its application in the field of electricity generation technologies - A literature review," Renewable and Sustainable Energy Reviews 82: 2346-2364.

Söderholm, P. and Klaassen, G. (2007), "Wind power in Europe: A simultaneous innovation-diffusion model," Environmental and Resource Economics 36: 163-190.

Söderholm, P. and Sundqvist, T. (2007), "Empirical challenges in the use of learning curves for assessing the economic prospects of renewable energy technologies," Renewable Energy 32: 2559-2578. 
Spanish Wind Energy Association (AEE) (2008), Wind Power 2008, Sector's Yearbook: Analysis and Data.

van der Zwaan, B. and Seebregts, A. (2004), "Endogenous learning in climate-energy-economic models: An inventory of key uncertainties," International Journal of Energy Technology and Policy 2: 130-141.

Weiss, M., Junginger, M., Patel, M.K. and Blok, K. (2010), “A review of experience curve analyses for energy demand technologies," Technological Forecasting and Social Change 77: 411-428.

Westerlund, J. (2007), “Testing for error correction in panel data," Oxford Bulletin of Economics and Statistics 69: 709-748.

Yeh, S. and Rubin, E.S. (2012), “A review of uncertainties in technology experience curves," Energy Economics 34: 762-771.

Yu, C.F., van Sark, W.G.J.H.M. and Alsema, E.A. (2011), "Unraveling the photovoltaic technology learning curve by incorporation of input price changes and scale effects," Renewable and Sustainable Energy Reviews 15: 324-337. 